\title{
Climate Change Impact Assessment for Sustainable Water Quality Management
}

\author{
Ching-Pin Tung ${ }^{1, *}$, Ting-Chuan Lee ${ }^{1}$, Wei-Ting Liao ${ }^{1}$, and Yun-Ju Chen ${ }^{2}$ \\ ${ }^{1}$ Department of Bioenvironmental Systems Engineering, National Taiwan University, Taipei, Taiwan \\ ${ }^{2}$ National Center for Disaster Reduction, Taipei, Taiwan
}

Received 15 October 2011, accepted 22 May 2012

\begin{abstract}
The goal of sustainable water quality management is to keep total pollutant discharges from exceeding the assimilation capacity of a water body. Climate change may influence streamflows, and further alter assimilation capacity and degrade river sustainability. The purposes of this study are to evaluate the effect of climate change on sustainable water quality management and design an early warning indicator to issue warnings on river sustainability. A systematic assessment procedure is proposed here, including a weather generation model, the streamflow component of GWLF, QUAL2E, and an optimization model. The Touchen creek in Taiwan is selected as the study area. Future climate scenarios derived from projections of four global climate models (GCMs) and two pollutant discharge scenarios, as usual and proportional to population, are considered in this study. The results indicate that streamflows may very likely increase in humid seasons and decrease in arid seasons, respectively. The reduction of streamflow in arid seasons may further degrade water quality and assimilation capacity. In order to provide warnings to trigger necessary adaptation strategies, an early warning indicator is designed and its 30 -year moving average is calculated. Finally, environmental monitoring systems and methods to prioritize adaptation strategies are discussed for further studies in the future.
\end{abstract}

Key words: Adaptive strategy, Assimilation capacity, Climate change, Early warning, Sustainable development

Citation: Tung, C.P., T. C. Lee, W.T.Liao, and Y.J.Chen, 2012: Climate change impact assessment for sustainable water quality management. Terr. Atmos. Ocean. Sci., 23, 565-576, doi: 10.3319/TAO 2012.05.22.01(WMH)

\section{INTRODUCTION}

The goal of sustainable development is to manage loadings resulting from social and economic development not to exceed eco-environmental carrying capacity. The carrying capacity for water quality management is the assimilation capacity of a body of water and is a function of water quality standards and streamflows. The sustainability of a river with respect to water quality can be defined as meeting current and future needs and keeping total pollutant discharges from exceeding assimilation capacity. Many studies (Elsner et al. 2010; Mantua et al. 2010; Forbes et al. 2011) have shown that climate change may significantly influence streamflow. Thus, assimilation capacities and river sustainability may be further degraded under climate change conditions. A long-term early warning system with

\footnotetext{
* Corresponding author

E-mail: cptung@ntu.edu.tw
}

a lead time of several 10 years is required to inform decision makers the status of river sustainability and to trigger proper adaptation strategies.

The domestic water supply is highly dependent upon surface water in Taiwan. In order to sustainably meet drinking water standards, it is necessary to keep the cumulative impacts of pollutant discharges below the assimilative capacity of a stream (Chen and Tung 2007). An assimilative capacity can be defined as the maximum allowable pollutant discharge into a stream without violating water quality standards. De Wit et al. (2007) simulated the impact of climate change on low-flow in the river Meuse with a hydrological model and indicated that climate change would decrease the average discharge of the Meuse during the low-flow season. Other research has already found that climate changes will cause increasing water temperature, decreasing streamflow in arid seasons and higher concentration of biochemical oxygen demand (BOD) and will reduce the assimilative 
capacity of rivers (Murdoch et al. 2000; Rush et al. 2004; Barczak et al. 2007). Moreover, some research constructs a river basin index to characterize governance indicators in river basins which apply a reliability test to assess the validity of the indicators and explore the relationship between the indicators and carrying capacity (Engle and Lemos 2010).

The largest challenge for sustainable water quality management is a changing climate. It is necessary to know when significant changes happen and how to respond. In year 2000, the Water Framework Directive (WFD) regulating actions of the European Union in the field of water policy was adopted. It treats the water quality problem as a complex dilemma and requires integrated water management in river basins based on a combined approach of water quality standards and emission limit values. This new legislation also expands the scope of water protection to surface waters and groundwater, and sets an obligation to achieve good water quality status for all waters in the European Union within a set deadline of 2015 (Kundzewicz and Krysanova 2010). To achieve the goals of WFD, sustainable management and adaptation strategies to climate change will have to incorporate a broad and multi-facetted array of pro-active measures that all contribute to a less vulnerable society (Hoff 2003). In addition, an early warning system is important capacity building to enable adaptation strategies. The World Conference on Disaster Reduction (2005) emphasized that an early warning system is extremely effective in saving lives, property and protecting vulnerable areas when natural hazards threaten. Hence, a satisfactory early warning system for water quality has to be created to cope with potential impact of climate change in Taiwan. Furthermore, a sustainable water management plan should normally consider a longer project life, such as several decades, thus necessitating a longer time horizon.

The following sections address methodologies which might lead to an early warning system: weather generation, hydrology and water quality simulation, an optimization model, an assessment of climate change effects upon water quality, and an indicator for the long-term to evaluate river sustainability. The results of a case study are presented and discussed, and then major findings and suggestions are provided.

\section{METHODOLOGY}

The procedure used for climate change impact assessment is shown in Fig. 1. First, current and future climate scenarios are setup based on historical weather data and GCMs projections. Then, a weather generation model is incorporated to produce daily temperature and precipitation for the streamflow model. As a rule, trend analysis requires long periods of record keeping (Interlandi and Crockett 2003; Bouza-Deaño et al. 2008). In this study the discharge data of 1981 - 1990 was chosen to validate the streamflow model. In addition, QUAL2E is used to simulate the concentrations of BOD and to determine a response matrix for an optimization model. QUAL2E requires design flow exceeding a probability of $75 \%$ which can be determined based on streamflow simulation. The response matrix is composed of the coefficients of the constraints in an optimization to determine the maximal allowable pollutant discharges. The allocated assimilation capacity for each sub-basin determined by the optimization model is used to assess river sustainability. Detail descriptions of sustainability appraisal can refer to Chen and Tung (2007).

\subsection{Climate Scenario Setup}

Current and future climate scenarios are setup to drive simulations to evaluate the possible impacts under different climatic conditions. The climate scenarios consist of monthly statistics, including monthly mean temperature and precipitation. The current climate scenario as a baseline is determined based on historical weather data. Then, the delta method is adopted to impose the possible changes of temperature and precipitation on the current weather statistics to form future climate scenarios. The changes in temperature and precipitation can be estimated from GCMs projections that can be obtained from Intergovernmental Panel on Climate Change (IPCC) Data Distribution Centre. The Delta method (Oehlert 1992) is applied, and the change of temperature in the study area in the future is assumed to be the same as the difference between the temperatures simulated

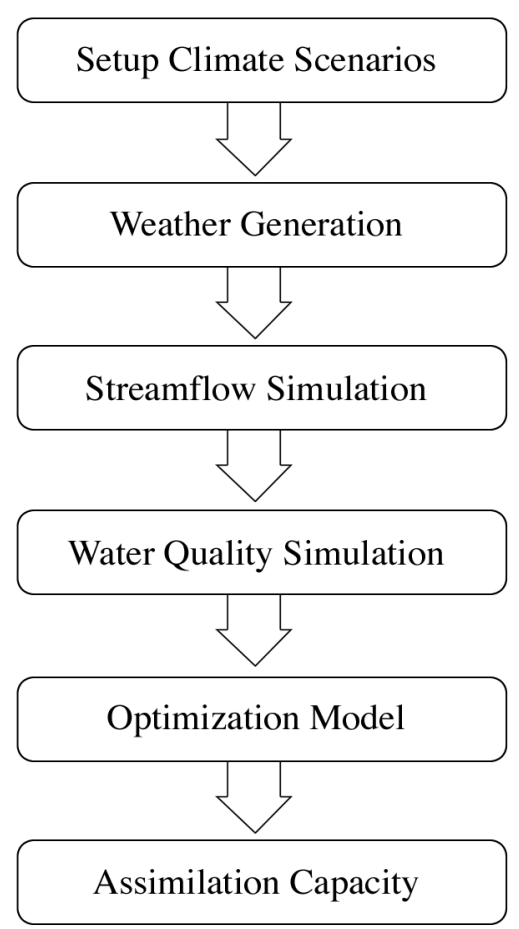

Fig. 1. The procedure of climate change impact assessment. 
by GCMs for future and current conditions at the nearest grid point. Thus, future climate scenarios can be estimated as

$\mu_{m T}^{\prime}=\mu_{m T}+\left(\mu_{m T, \text { Future }}-\mu_{m T, \text { Current }}\right)$

where $\mu_{m T}$ and $\mu_{m T}^{\prime}$ are current and future mean monthly temperatures $\left({ }^{\circ} \mathrm{C}\right)$, respectively, and $\mu_{m T, \text { Current }}$ and $\mu_{m T, \text { Future }}$ are simulated mean monthly temperatures $\left({ }^{\circ} \mathrm{C}\right)$ under current and future climate conditions, respectively. Change in precipitation is assumed to be the ratio of the precipitation under future conditions to that under current conditions:

$\mu_{m P}^{\prime}=\mu_{m P} \times\left(\mu_{m P, \text { Future }} / \mu_{m P, \text { Current }}\right)$

where $\mu_{m P}$ and $\mu_{m P}^{\prime}$ are current and future mean monthly precipitation values $(\mathrm{cm})$, respectively, and $\mu_{m p, \text { Current }}$ and $\mu_{m P, \text { Future }}$ are simulated mean monthly precipitation values (cm) under current and future climate conditions, respectively.

\subsection{Weather Generation Model}

A weather generation model (Pickering et al. 1988; Tung and Haith 1995) is used to generate daily weather data based on climate scenarios. Mean daily temperature is generated by a first order autoregressive equation:

$T_{i}=\mu_{T}+\rho\left(T_{i-1}-\mu_{T}\right)+v_{i} \sigma_{T}\left(1-\rho^{2}\right)^{0.5}$

where $\mu_{T}$ is mean monthly temperature $\left({ }^{\circ} \mathrm{C}\right), \sigma_{T}$ is standard deviation of temperature $\left({ }^{\circ} \mathrm{C}\right), \rho$ is lag-one autocorrelation, and $v_{i}$ is a normal random variant.

Precipitation events and amounts are generated separately. The events are generated by the Markov chain; amounts are produced based on the Weibull distribution. It is a wet day event, if the following conditions are met.

$\varepsilon \leq\left\{\begin{array}{l}P(W \mid W) \text { if previous day is wet day } \\ P(W \mid D) \text { if previous day is dry day }\end{array}\right.$

where $\varepsilon$ is a random number with uniform distribution in the range of $[0,1], P(W \mid W)$ is a wet day probability if a given previous day is a wet day, and $P(W \mid D)$ is a wet day probability if a given previous day is a dry day. If it is a wet day, the rainfall amount is generated based on a single-parameter Weibull distribution (Selker and Haith 1990)

$P=\left\{\mu_{P} \times[-\ln (1-R N D)]^{(4 / 3)}\right\} / 1.191$

where $\mu_{P}$ is mean wet day precipitation (cm).

\subsection{Generalized Watershed Loading Functions (GWLF)}

The streamflow component of the Generalized Watershed Loading Function (GWLF) (Haith and Shoenaker 1987; Haith et al. 1992) is used to simulate streamflow in this study. The GWLF model has been utilized widely for climate change issues. For instance, Schneiderman et al. (2010) develops a common three-step approach to the analysis of the catchment hydrology impacted by climate change with the GWLF Model. The model is a conceptual water balance model. Streamflows are equal to the sum of surface runoff $\left(Q_{t}\right)$ and groundwater discharge $\left(G_{t}\right)$, which surface runoff is calculated by Soil Conservation Service (SCS) Curve Number method (Ogrosky and Mockus 1964) and groundwater discharge is estimated by assuming shallow saturated zone as a linear reservoir. Groundwater discharge is estimated by Eq. (6).

$G_{t}=r S_{t}$

where $r$ is a recession coefficient and $S_{t}$ is a storage of shallow saturated zone $(\mathrm{cm})$.

To estimate groundwater discharge, water content of shallow saturated zone is traced by a water balance equation as follows:

$S_{t+1}=S_{t}+P C_{t}-G_{t}-D_{t}$

where $P C_{t}(\mathrm{~cm})$ is percolation and $D_{t}$ is deep seepage (cm) during period $t$ (day). Percolation happens when soil moisture of unsaturated zone exceeds field capacity:

$P C_{t}=\operatorname{Max}\left[0, U_{t}+I_{t}-E T_{t}-U^{*}\right]$

where $I_{t}$ is infiltration and $E T_{t}$ is evapotranspiration during period $t$, and $U^{*}$ is maximum soil water capacity. Infiltration is equal to rainfall $\left(R_{t}\right)$ minus surface runoff $\left(Q_{t}\right)$ as follows:

$I_{t}=R_{t}-Q_{t}$

Evapotranspiration is affected by atmospheric condition, land uses, and soil moisture content, which is described as Eq. (10).

$E T_{t}=\operatorname{Min}\left[k_{c t} \times P E T_{t}, U_{t}+I_{t}\right]$

where $k_{c t}$ is land cover coefficient, $P E T_{t}$ is potential evapotranspiration which is calculated by the Hamon equation (Hamon 1961). The soil moisture of unsaturated zone in Eqs. (8) and (10) is calculated as Eq. (11). The conceptual 
water balance is run in a daily time step for soil moisture balance.

$U_{t+1}=U_{t}+I_{t}-E T_{t}-P C_{t}$

\subsection{Enhanced Stream Water Quality Model (QUAL2E)}

The QUAL2E model is developed by US EPA and can be used as a good decision making tool in river basin management for the estimation of discharged wastewater effects on the resulting quality of a recipient stream (Ghosh and McBean 1998). The simulation model illustrates important physical, biological and chemical processes and their interactions for particular compounds associated with water quality via a set of partial differential equations. The QUAL2E can simulate multiple waste discharges, withdrawals, tributary flows, and incremental inflow and outflow. To assess a stream's assimilative capacity, this study focuses on critical BOD conditions during low flow periods. After calibrating and validating parameters, the QUAL2E can be applied to determine a response matrix based on several simulation runs. Each run simulates concentrations at all downstream checking points from one discharging pollutant unit at an upstream location $i$ with a designed flow, such as the flow which is exceeded $75 \%$ of the time $\left(\mathrm{Q}_{75}\right)$. If there are $n$ discharge points, it needs $n$ simulations to complete the matrix. The nonpoint source pollution is treated as background pollution during low flows in this study. If best management practices are applied to reduce nonpoint sources, the response matrixes should be recalculated.

\subsection{Optimization Model}

The goal of the optimization model, which is subject to constraints of the prescribed water quality standards, is to maximize allowable pollutant discharges, e.g., assimilation capacity. The formulation of the model is described as below including decision variables, objective function, and constraints.

\subsubsection{Decision Variables}

The optimization model attempts to maximize total discharges without violating water quality standards. A watershed can be divided into several sub-basins and a decision variable $W_{i}$ is defined as allowable pollutant discharges from sub-basin $i$.

\subsubsection{Objective Function}

There may be different objectives, including maximal benefits, minimal costs, equity, and maximal total allowable pollutant discharges. They can also be combined to form multi-objectives. The objective function to maximize allowable pollutant discharges is considered here and can be easily written as follows.

$\operatorname{Max} Z=\sum_{i=1}^{n} W_{i}$

where $n$ is the number of sub-basins within a watershed.

\subsubsection{Constraints}

The major constraint to the problem of water quality management is pollutant discharge not resulting in violating water quality standards. If the numbers of discharge and checking points are $n$ and $m$ respectively, the constraints to meet BOD standard can be described as Eq. (13).

$\left[\begin{array}{cccc}r_{11} & r_{12} & \cdots & r_{1 n} \\ r_{21} & r_{22} & \cdots & r_{2 n} \\ \vdots & \vdots & \ddots & \vdots \\ r_{m 1} & r_{m 2} & \cdots & r_{m n}\end{array}\right]\left[\begin{array}{c}W_{1} \\ W_{2} \\ \vdots \\ W_{n}\end{array}\right] \leq\left[\begin{array}{c}c_{1} \\ c_{2} \\ \vdots \\ c_{m}\end{array}\right] \forall W_{i} \geq 0, i=1, \ldots, n$

where $r_{i j}$ is a response coefficient to describe the concentration of BOD at checking point $j$ resulting from one unit pollutant discharge at upstream location $i$ and $c_{j}$ is the BOD water quality standard for check point $j(I=1,2, \ldots, n ; j=$ $1,2, \ldots, m)$. The response matrixes in Eq. (13) can be determined by the QUAL2E model. If the pollutant discharge point $i$ is located in downstream of checking point $k$, the value of response coefficient $r_{i k}$ is 0 .

\subsection{Early Warning Indicator (EWI)}

An early warning system can provide valuable information with a certain lead time and allow decision makers implement proper responses. In the past, most of early warning systems focused on a shorter lead time for disaster reduction, but not a long-term warning regime to revise strategies or management plans for mitigating the effects of climate change. In this study, the lead time for early warning systems is classified into long-term, short-term, seasonal and real-time (as Table 1) for different administrative implements. Since climate change study has significant uncertainty and sustainable water quality management plan should have planning horizon of several decades, an early warning indicator (EWI) is established to issue warnings and trigger adaptive strategies.

The main principle for sustainable management strategies is to ensure cumulative loadings not exceed the carrying capacity as described by Sadler (1994). Thus, the EWI for each sub-basin $i$ is represented in Eq. (14) to evaluate whether allocated loadings are exceeded. 
Table 1. Classification of early warning systems.

\begin{tabular}{cll}
\hline $\begin{array}{c}\text { Early } \\
\text { Warning System }\end{array}$ & $\begin{array}{c}\text { Leading } \\
\text { Time-scale }\end{array}$ & \multicolumn{1}{c}{ Responses } \\
\hline Long-term & Decade & Plan Modification \\
Short-term & Year & Management Adjustment \\
Seasonal & Month & Management Adjustment \\
Real-time & Day or Hour & Operational Response \\
\hline
\end{tabular}

$\mathrm{EWI}_{i}=\frac{P_{i}}{W_{i}}$

where $P_{i}$ is total pollutant discharges from sub-basin $i$. In Eq. (12), the sustainability of a stream will sustain if the $\mathrm{EWI}_{i} \leqq 1$ for $\forall i$. Conversely, $\mathrm{EWI}_{i}>1$ means total pollutant discharges from sub-basin $i$ exceeding its allocated loading which may result in the degradation of water quality and a violation of water quality standards downstream.

\section{A CASE STUDY}

\subsection{Study Area}

The Touchen creek watershed which drains towards the Taiwan Strait (as Fig. 2) located in northern Taiwan was chosen as a study area. The watershed area is $565.4 \mathrm{~km}^{2}$ and river length is $63.4 \mathrm{~km}$. The major land uses are forestry, agriculture, and urban habitation. The Touchen creek is a very important water resource supplying drinking water to the Hsinchu region of Taiwan. The water quality standard listed in Table 2 is defined by the Environmental Protection Administration of Taiwan to ensure that water is suitable for various surface water utilization purposes. Most reaches of the Touchen creek are required to meet at least the second level of water quality standards. The Touchen creek contains eight water quality monitoring stations: Paoshan, Ruifen, Neiwan, Chudong, Chulin, Chongcheng, Touchen and Sichou (from upstream to downstream, respectively). The water quality of the reaches above the Ruifen station must meet the first level of water quality standards, while the reaches below Sichou station only need to meet the third level standard. Other reaches must meet the second level standard. The pollutant concerned in this study is BOD. The background concentration of BOD is relatively small and neglectable in the study watershed. Further, major contributors of BOD are point sources, and thus BOD from nonpoint source is not considered.

\subsection{Climate Scenarios}

The transitional experiments via CGCM2, HADCM3, CSIRO, CCSR, GFDLR30, ECHAM4 models based on SRES A2 and B2 scenarios are considered to establish future climate scenarios in this study (Ruosteenoja et al. 2007; Wetterhall et al. 2009). The GCMs projects can be obtained from the IPCC Data Distribution Centre. Table 3 shows the correlations between the GCMs projections and local

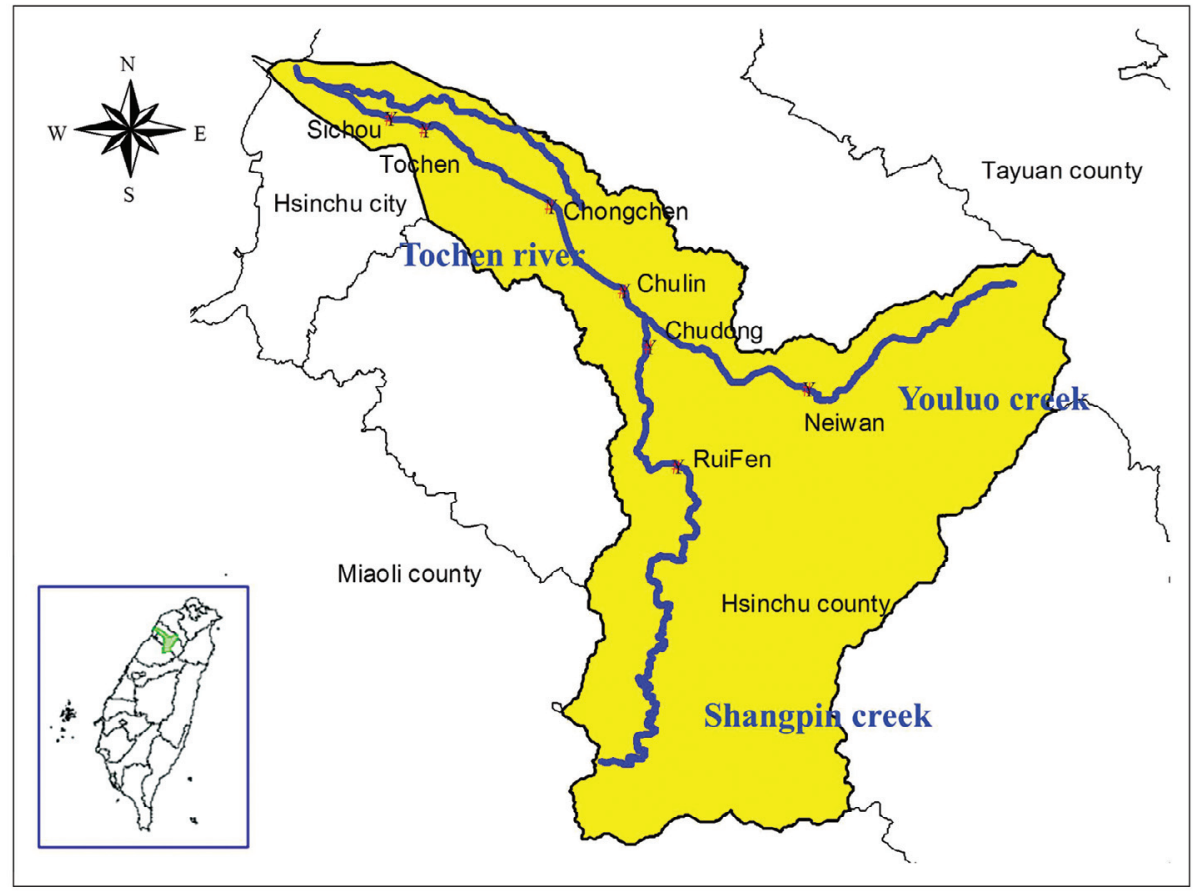

Fig. 2. Study Area - the Touchen creek, Hsinchu County, Taiwan. 
Table 2. Water quality standards for freshwater in Taiwan.

\begin{tabular}{l|cccccc}
\hline & DO $\left(\mathbf{m g ~ l}^{-1}\right)$ & BOD $\left(\mathbf{m g ~ l}^{-1}\right)$ & SS $\left(\mathbf{m g ~ l}^{-1}\right)$ & E-coli $(\mathbf{C F U} / \mathbf{1 0 0 ~} \mathbf{~ m l})$ & NH3-N $\left(\mathbf{m g ~ l}^{-1}\right)$ & TP $\left(\mathbf{m g ~ ~ ^ { - 1 } )}\right.$ \\
\hline First & $\geqq 6.5$ & $\leqq 1$ & $\leqq 25$ & $\leqq 50$ & $\leqq 0.1$ & $\leqq 0.02$ \\
Second & $\geqq 5.5$ & $\leqq 2$ & $\leqq 25$ & $\leqq 5000$ & $\leqq 0.3$ & $\leqq 0.02$ \\
Third & $\geqq 4.5$ & $\leqq 4$ & $\leqq 40$ & $\leqq 10000$ & - & - \\
Fourth & $\geqq 3.0$ & - & $\leqq 100$ & - & - & - \\
Fifth & $\geqq 2.0$ & - & $\leqq 100$ & & - \\
\hline
\end{tabular}

Table 3. Correlation between GCMs baseline and local climate.

\begin{tabular}{l|cccccc}
\hline & CGCM2 & HADCM3 & CSIRO & CCSR & GFDLR30 & ECHAM4 \\
\hline Rainfall & 0.61 & 0.62 & -0.61 & 0.62 & 0.46 & 0.09 \\
Temperature & 0.98 & 0.98 & 0.97 & 0.98 & 0.96 & 0.95 \\
\hline
\end{tabular}

climate for the period 1961 - 1990. The projected rainfall from CSIRO and ECHAM4 models have low or negative correlation and may cause high uncertainty. Thus, these two models' projections are not used further to setup future climate scenarios.

\subsection{Experimental Design}

The purpose of this study is to establish an early warning system. In the meantime, the possible impacts of climate change on streamflow and water quality are also of concern. Thus, the possible changes of streamflow and BOD concentrations are evaluated under projected future climate conditions for three time periods, S: 2010 - 2039, M: 2040 - 2069, and L: 2070 - 2099, respectively. For the early warning study, the trend of $\mathrm{EWI}_{i}$ is analyzed by estimating a 30 -year moving average for each sub-basin. In order to reduce computation demands, the moving average is calculated with the interval of 10 years. If it is necessary, the interval can be reduced. Future climate scenarios for different time periods are determined by Eqs. (1) and (2), in which $\mu_{m T, \text { Current }}$ and $\mu_{m P, \text { Current }}$ are averaged from the GCM base simulation for 1961 - 1990 and $\mu_{m T, \text { Future }}$ and $\mu_{m P, \text { Future }}$ are average values for corresponding periods.

To evaluate the climate change impacts upon BOD concentrations or an EWI trend, a $\mathrm{Q}_{75}$ flow must be determined based upon simulated streamflows for each 30-year period. Two future pollutant discharge scenarios are considered: (1) as usual; and (2) proportional to a population. The increase of pollutant discharges is assumed to be proportional to population growth only.

\section{RESULTS}

The GWLF and QUAL2E models are verified and then are applied further to evaluate the impacts of climate change. Then, EWI is calculated for different periods to provide early warning information. More discussion on simulation results are addressed after this section.

\subsection{Verifications of GWLF and QUAL2E}

The streamflow component of GWLF is verified first. The parameters required for the GWLF are determined according to the land uses and soil texture of the study area. The streamflow and weather data of $1981-1990$ are used to verify the model. Figures $3 a$ and $b$ show the simulated and observed monthly and mean monthly flows. The R-squares for monthly and mean monthly flows are 0.75 and 0.90 , respectively. The GWLF model can provide a reasonable streamflow simulation. A two year data set, 1996 and 1999, is used to calibrate and validate parameters for simulating DO and BOD for QUAL2E. Figure 4a shows the results of calibration. In Fig. 4b, the outcome of validation indicates QUAL2E can provide a reasonable simulation for DO and BOD concentrations. Verification studies state both GWLF and QUAL2E models can provide reasonable simulation for the study area, and thus are further applied to evaluate the impacts of climate change.

\subsection{Climate Change Impact Assessment}

Figures $5 \mathrm{a}$ and $\mathrm{b}$ show the climate change impacts upon streamflows of arid (November through April next year) and humid (May through October) seasons based upon four GCMs' A2 and B2 scenarios, respectively. A1though the consistent changing trend of streamflow among four GCMs' scenarios cannot be found, the results provide information leading to the conclusion that a humid season tends to have more flows while arid season tends to have 

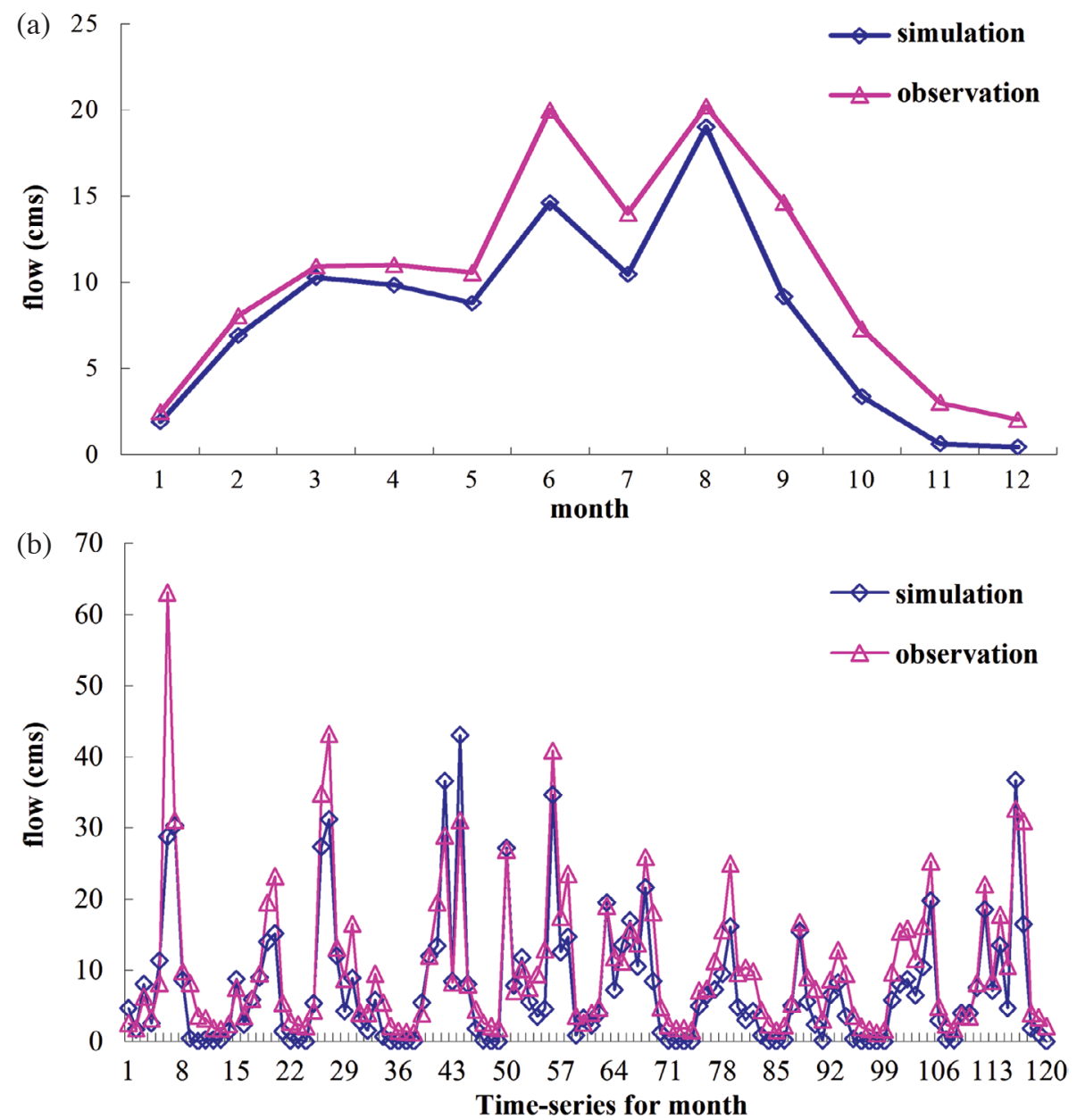

Fig. 3. Verification study for the GWLF model. (a) Average monthly streamflow of the period $1981-1990$ (R² = 0.90). (b) Monthly streamflows of the period $1981-1990\left(\mathrm{R}^{2}=0.75\right)$.

(a)
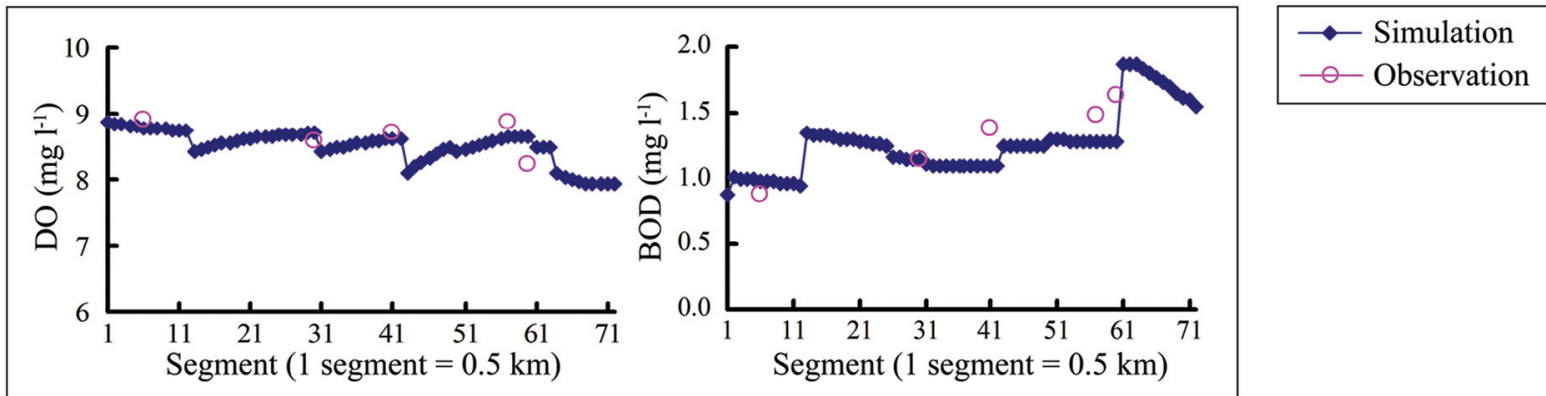

(b)

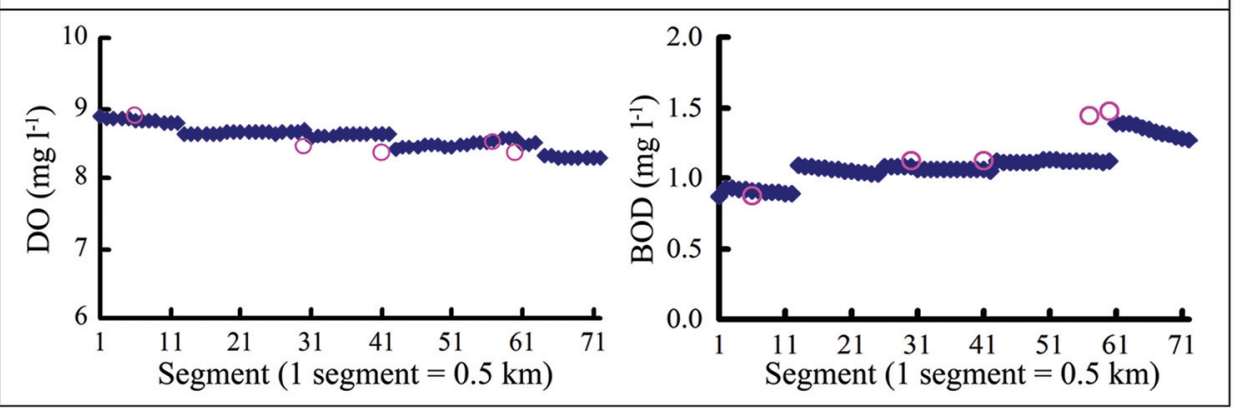

Fig. 4. Results of calibration and validation of QUAL2E model for the Touchen creek. (a) Calibration - 1996. (b) Validation - 1999. 
(a)

\begin{tabular}{|lll|}
\hline$\square \mathrm{CGCM} 2 \mathrm{~A} 2 \mathrm{~S}$ & $\square \mathrm{CCSRA2L}$ & $\square \mathrm{HADCM} A 2 \mathrm{~L}$ \\
$\square \mathrm{CGCM}$ 2A2L & $\square$ GFDL-R30A2M & $\square$ CCSRA2M \\
$\square \mathrm{HADCM} A 2 \mathrm{M}$ & $\square \mathrm{CGCM} 2 \mathrm{~A} 2 \mathrm{M}$ & $\square$ GFDL-R30A2S \\
$\square \mathrm{CCSRA2S}$ & $\square \mathrm{HADCM} A 2 \mathrm{~S}$ & $\square$ GFDL-R30A2L
\end{tabular}

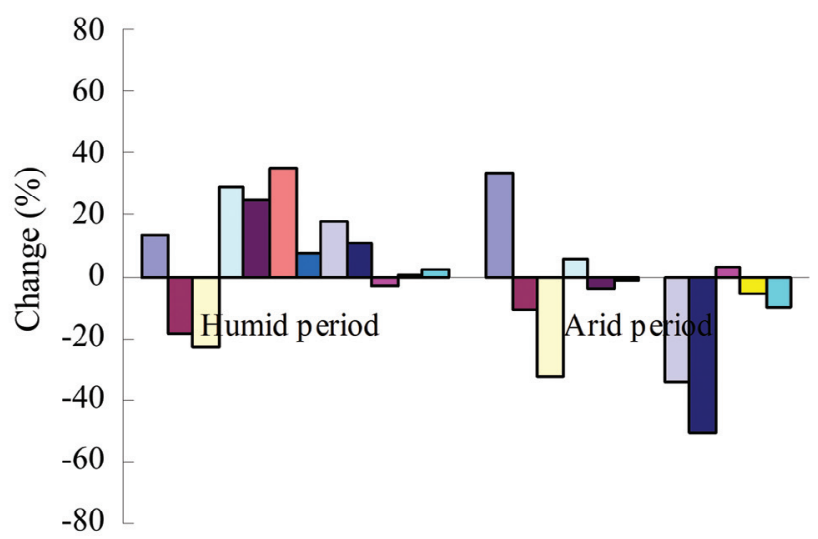

(b)

\begin{tabular}{|lll|}
\hline$\square$ CGCM2B2S & $\square$ CCSRB2L & $\square$ HADCM3B2L \\
$\square$ CGCM2B2L & $\square$ GFDL-R30B2M & $\square$ CCSRB2M \\
$\square$ HADCM3B2M & $\square$ CGCM2B2M & $\square$ GFDL-R30B2S \\
$\square$ CCSRB2S & $\square$ HADCM3B2S & $\square$ GFDL-R30B2L
\end{tabular}

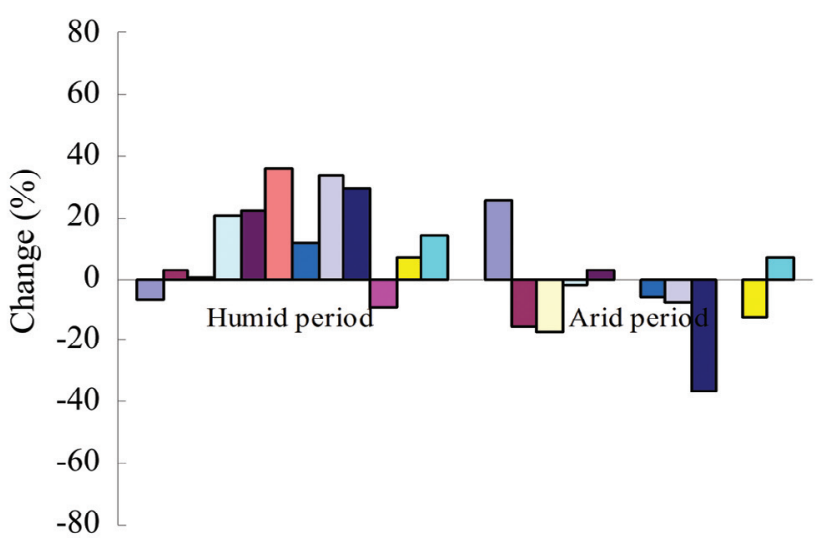

Fig. 5. Climate change impacts on streamflows. (a) Climate Change Scenario-A2. (b) Climate Change Scenario-B2.

fewer flows. The assimilation capacity is determined based on $\mathrm{Q}_{75}$ which is significantly influenced by low flow reduction. Thus, the reduction of low flows in an arid season may significantly degrade water quality.

Figures $6 \mathrm{a}$ and $\mathrm{b}$ illustrate the climate change impacts on BOD concentration based on CGCM's projections as an example. There are significant changes of BOD concentrations under climate change conditions. The BOD concentrations may increase from the period 2010 - 2039 to the period 2070 - 2099. Most changes happen right after pollutant discharge points. The water quality standard for drinking water requires keeping a BOD concentration less than $2 \mathrm{mg} \mathrm{l}^{-1}$ for the study creek, and the downstream river after the $25^{\text {th }}$ segment may violate water quality standards in the future. There is an inlet contributed by wastewater from a water treatment plant near the $54^{\text {th }}$ segment. Thus the water quality may not meet drinking water standards after the period 2030 - 2059. It may require a more strict pollutant control plan or better water treatment technology which may require significant costs in future. The results from Figs. 6a and b also imply that extreme low flows have consistent reduction trends, while the consistent trend of mean flows for either humid or arid seasons cannot be identified in Figs. 5a and b.

\subsection{Analysis of Early Warning Indicator (EWI)}

Eight simulation runs composed of four GCMs and two SRES scenarios are used to determine mean, upper, and lower bounds of EWI for each time period. The worst and best values of EWI are selected to be the upper and lower bounds for different time periods, respectively. There are four major pollutant discharge points, Nei-He, Chu-Dong, Kan-Sia, and Nei-Ya drainages. Thus, the values of EWI calculated for the four associated sub-basins are provided in Figs. 7 and 8. According to Fig. 7, if pollutant discharges are usual, the sub-basins of Chu-Dong and Nei-Ya drainages would have significant violation of sustainability criterion $(E W I \leq 1)$ under all climate change conditions. The Nei-Ya sub-basin is in the worst condition and is the most vulnerable area. If both pollutant discharge increases and climate change are considered, Fig. 8 indicates that the sustainability status may become worse for all sub-basins. The Nei-He sub-basin can still keep its sustainability, but the total pollutant discharge from the Kan-Sia sub-basin may exceed its allocated assimilation capacity after the period 2040 - 2069.

\section{DISCUSSION}

According to the results, climate change will reduce the stream assimilative capacity and degrade the river sustainability. The early warning system must be established to issue warnings and trigger proper actions. However, the uncertainty of the results may limit decision making capacities. In addition, making decisions based on early warning information is crucial to sustainability.

\subsection{The Uncertainty of Climate Change Study}

Obtaining reliable forecasts of water quality range shifts under climate change is a crucial challenge for water resource management. The outcome may result from GCM projections, downscaling methods, and simulation models. Six GCM projections have been tested with local climate, and two of them are not selected for further study because of different tendency. However, Figs. 5a and b shows significant different results of impact assessment of the rest four GCMs on streamflows among different scenarios. For 
example, the results indicates that streamflows in a humid season based on the CGCM A2 scenario show increasing in a short-term period and decreasing in both mid and long term periods, while those based on HADCM3's A2 present increasing streamflows for all three periods. Thus, ensemble results may be necessary for providing information to decision makers. Figures 7 and 8 show an estimated EWI having more consistent trends among mean, upper, and lower bounds.

Since long-term early warning information has significant uncertainty, it is necessary to establish a short-term early warning system (as defined in Table 2) based on environmental monitoring. In Fig. 9, if the trend of long-term climate change impact has a similar direction as the trend based on environmental monitoring, it is necessary to pay more attention on the early warning information. On the other hand, if the predicted trends from climate change study and environmental monitoring are different, the information may require further studies to reduce uncertainty. Environmental monitoring systems will play a very important role in developing and implementing adaptation strategies.

\subsection{Priorities of Adaptation Strategies}

A long-term early warning system requires triggering proper adaptations to reduce climate change effects. However, climate change impact assessment and adaptation involve a longer time horizon and significant uncertainty. Thus, it is very important not only to evaluate suitable adaptive strategies but also to determine their priorities based upon multiple criteria. Based on the research by Loë et al. (2001), Burton et al. (2002) and the UK Climate Impacts Programme (UKCIP) Adaptation Wizard, the following criteria were proposed for screening the broad range of
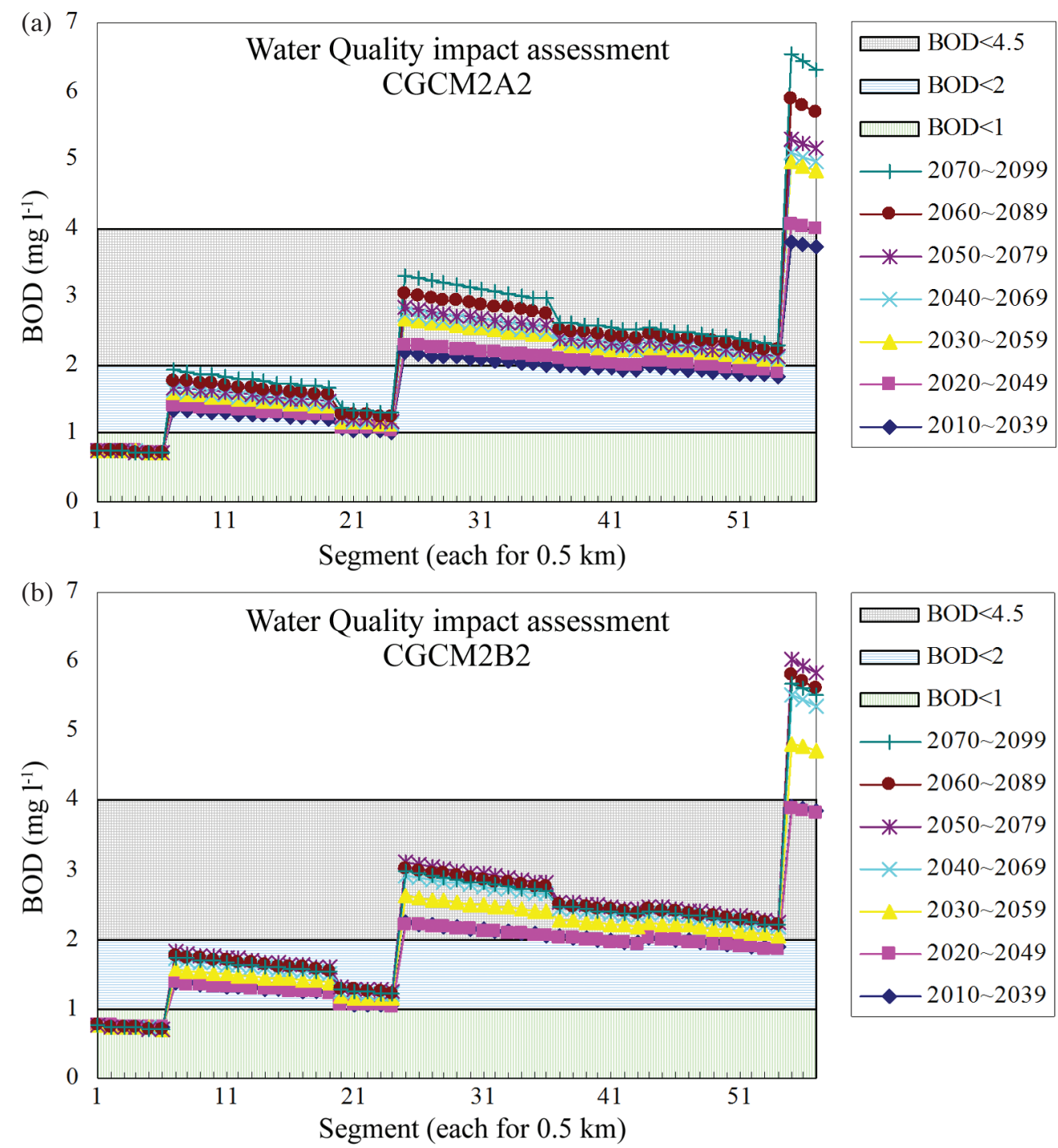

Fig. 6. Climate change impacts on water quality based on CGCM projections. (a) Climate Change Scenario-A2. (b) Climate Change Scenario-B2. 

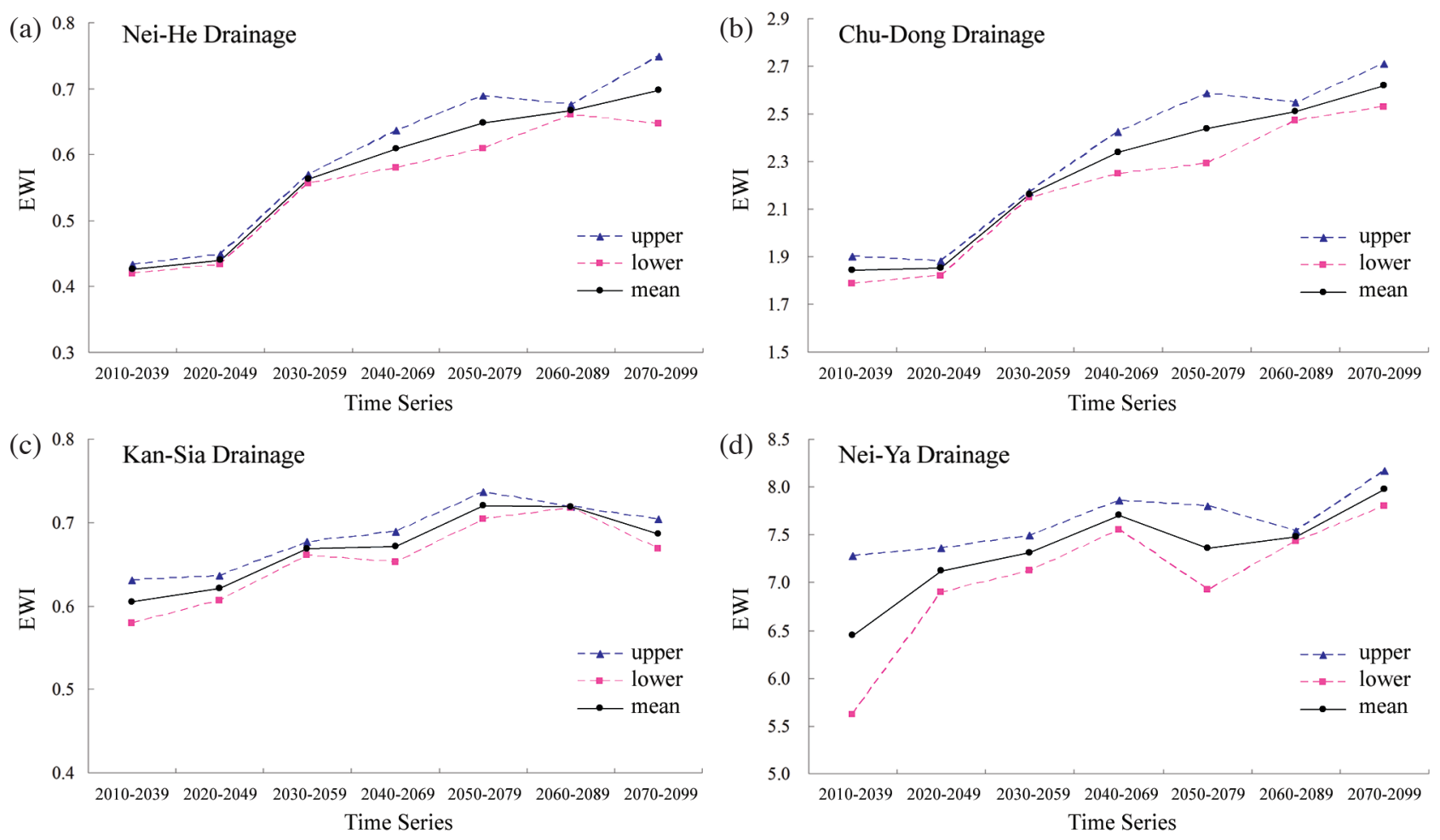

Fig. 7. Trend in Early Warning Indicator (EWI) per usual pollutant discharges.
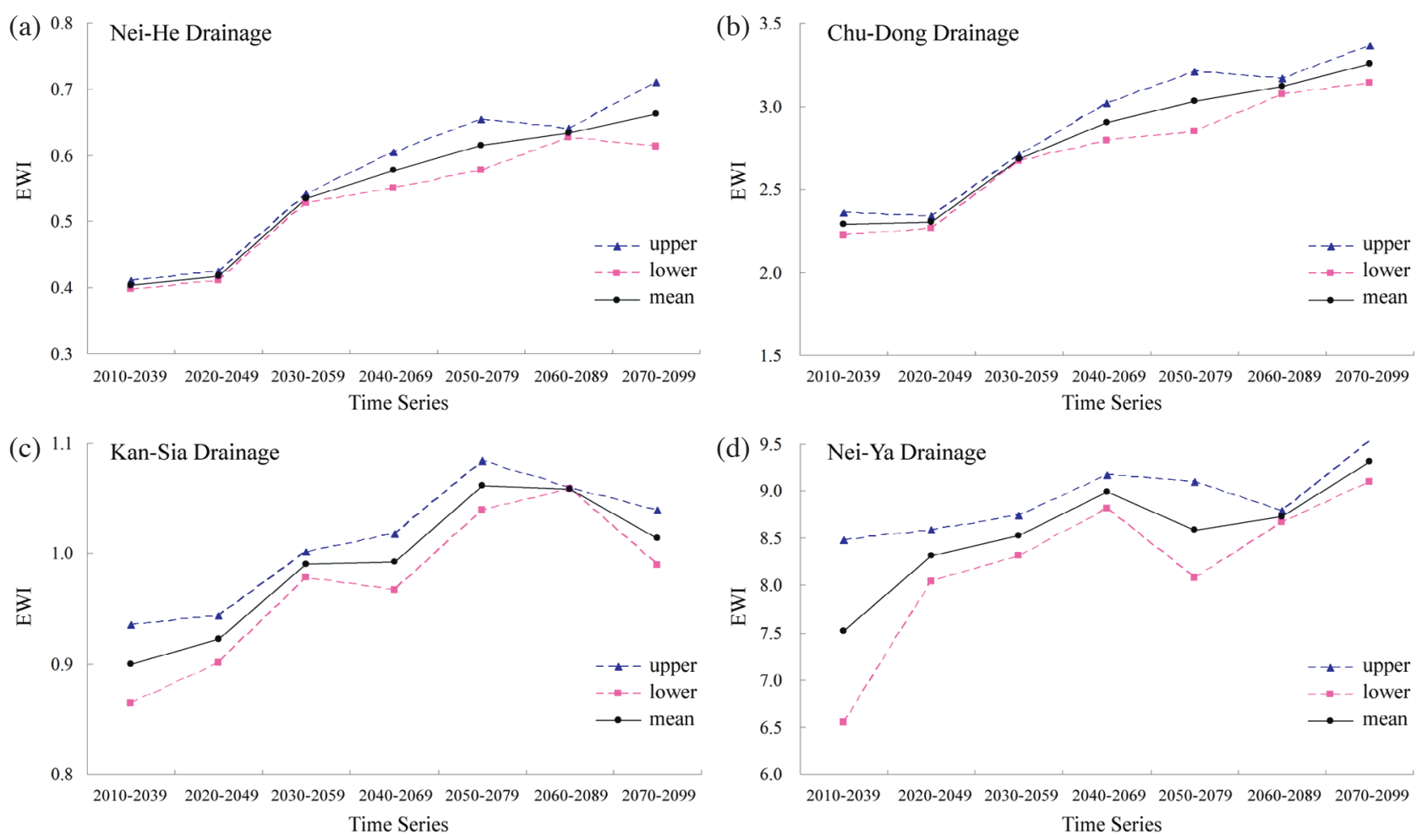

Fig. 8. Trend of Early Warning Indicator (EWI) with pollutant discharge increases proportional to population growth. 


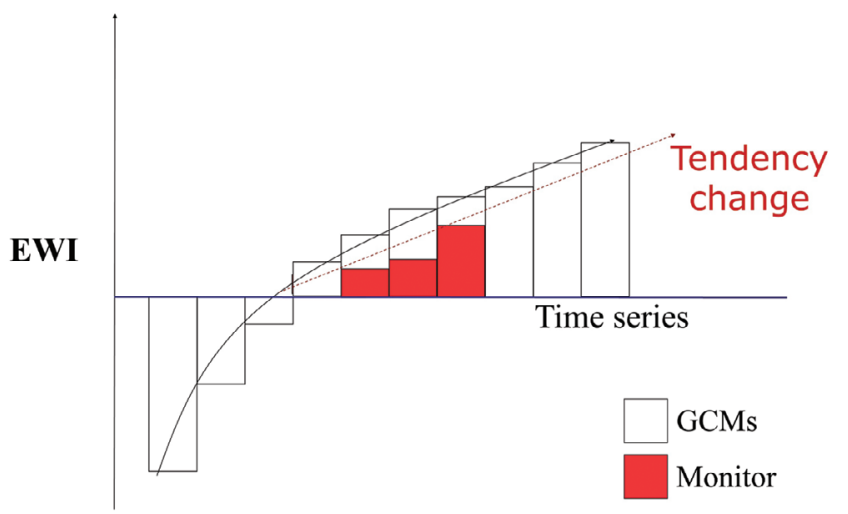

Fig. 9. Trends of long-term and short-term EWI based on GCMs projections and environmental monitoring.

available options: (1) No regrets; (2) Reversibility; (3) Minimum of environmental impacts; (4) Cost effectiveness; (5) Equity; (6) Reducing vulnerability; (7) Ease of implementation; (8) Effectiveness. The priorities of adaptive strategies may further be determined based on the eight principles by Analytical Hierarchy Process or Hierarchical Additive Weighting Method.

\section{CONCLUSIONS}

This study proposes a procedure to assess the climate change impacts on sustainable water quality management. Further, an early warning indicator is also designed to issue warnings to trigger necessary adaptation strategies. The procedure includes a climate scenario setup, weather generation model, hydrological simulation, water quality simulation, and optimization to determine assimilation capacity. The results indicate that climate change may cause very likely tendency to increase streamflows in humid seasons and decrease flows in arid seasons, respectively, though the consistence cannot be found among different GCMs' scenarios. The reduction of low flow further influences water quality. The BOD concentration may not meet water quality standards after the year 2050s. Adaptation strategies for sustainable water quality management are crucial.

A long-term early warning indicator is designed as total pollutant discharges divided by allocated assimilation capacity for each sub-basin. The indicator can not only point out which sub-basin is the most vulnerable under climate change conditions but also provide information when sustainability of a sub-basin may loose. To reduce uncertainty, a short-term early warning based on environmental monitoring systems is suggested. If both long-term and short-term warnings have issued the same tendency towards worse water quality, the decision makers may take notice of this information and execute adaptation strategies urgently. To implement the early warning system in a practical way, governors and residents need to reach an agreement after consultation. Huntjens et al. (2010) also suggests that bottom-up governance is not a straightforward solution to water management problems in large-scale, complex, multipleuse systems, such as river basins. Instead, all the regimes being analyzed are in a process of finding a balance between bottom-up and top-down governance. Further, early warning systems could be adjusted every year in response to the arrival of new information (Hallegatte 2009).

A simple downscaling method, the delta method, is used in this study. The area of study watershed is much smaller than the grid size of GCMs. A more sophisticated downscaling method may be required. Fortunately, GCM projections are improving and more SRES experiments, such as A1B and B1, have been done. The application of GCMs projections should be updated accordingly. Climateinduced disasters have been observed all around the world in recent years, and climate change studies also suggest that more intensive and frequent extreme events may happen in the future. Thus, taking actions to adapt to future climate and reduce impacts is very necessary. Moreover, further studies on prioritizing adaptations with multiple criteria, establishing environmental monitoring system, and short-term early warning systems are strongly suggested.

Acknowledgements This work has been funded by National Science Council of Taiwan through the program titled "Study of Environmental Carrying Capacity, Total Mass Control, Strategic Environmental Assessment - Water Resources (II)" and "Study of Environmental Carrying Capacity, Total Mass Control, Strategic Environmental Assessment - Water Resources (III)."

\section{REFERENCES}

Barczak, S. and R. Carroll, 2007: Climate change implications for Georgia's water resources and energy future. Proceedings of the 2007 Georgia Water Resources Conference, 27-29 March 2007.

Bouza-Deaño, R., M. Ternero-Rodríguez, and, A. J. Fernández-Espinosa, 2008: Trend study and assessment of surface water quality in the Ebro River (Spain). J. Hydrol., 361, 227-239, doi: 10.1016/j.jhydrol.2008.07. 048. [Link]

Burton, I., S. Huq, B. Lim, O. Pilifosova, and E. L. Schipper, 2002: From impacts assessment to adaptation priorities: The shaping of adaptation policy. Clim. Policy, 2, 145159, doi: 10.1016/S1469-3062(02)00038-4. [Link]

Chen, Y. J. and C. P. Tung, 2007: New Criteria for Sustainable Water Quality Management. J. Am. Water Resour. Assoc., 43, 372-383, doi: 10.1111/j.1752-1688. 2007.00029.x. [Link]

De Wit, M., H. Buiteveld, and W. van Deursen, 2007: Klimaatverandering en de afvoer van Rijn en Maas. Ri- 
jkswaterstaat RIZA memo WRR/2007-006, Lelystad. (in Dutch)

Elsner, M. M., L. Cuo, N. Voisin, J. S. Deems, A. F. Hamlet, J. A. Vano, K. E. B. Mickelson, Se-Yeun Lee, and D. P. Lettenmaier, 2010: Implications of 21st century climate change for the hydrology of Washington State. Clim. Change, 102, 225-260, doi: 10.1007/s10584-01 0-9855-0. [Link]

Engle, N. L. and M. C. Lemos, 2010: Unpacking governance: Building adaptive capacity to climate change of river basins in Brazil. Global Environ. Change, 20, 4-13, doi: 10.1016/j.gloenvcha.2009.07.001. [Link]

Forbes, K. A., S. W. Kienzle, C. A. Coburn, J. M. Byrne, and J. Rasmussen, 2011: Simulating the hydrological response to predicted climate change on a watershed in southern Alberta, Canada. Clim. Change, 105, 555576, doi: 10.1007/s 10584-010-9890-x. [Link]

Ghosh, N. C. and E. A. McBean, 1998: Water quality modeling of the Kali River, India. Water Air Soil Pollut., 102, 91-103, doi: 10.1023/A:1004912216834. [Link]

Haith, D. A. and L. L. Shoenaker, 1987: Generalized watershed loading functions for stream flow nutrients. $J$. Am. Water Resour. Assoc., 23, 471-478, doi: 10.1111/ j.1752-1688.1987.tb00825.x. [Link]

Haith, D. A., R. Mandel, and R. S. Wu, 1992: Generalized Watershed Loading Functions Version 2.0 User's Manual. Department of Agricultural and Biological Engineering, Cornell University.

Hallegatte, S., 2009: Strategies to adapt to an uncertain climate change. Global Environ. Change, 19, 240-247, doi: 10.1016/j.gloenvcha.2008.12.003. [Link]

Hamon, W. R., 1961: Estimating potential evapotranspiration. Proc. Am. Soc. Civ. Eng., J. Hydraul. Div., 87, 107-120.

Hoff, H., L. Bouwer, G. Berz, W. Kron, and T. Loster, 2003: Risk management in water and climate - The role of insurance and other financial services. Dialogue on Water and Climate.

Huntjens, P., C. Pahl-Wostl, and J. Grin, 2010: Climate change adaptation in European river basins. Reg. Environ. Change, 10, 263-284, doi: 10.1007/s10113-0090108-6. [Link]

Interlandi, S. J. and C. S. Crockett, 2003: Recent water quality trends in the Schuylkill River, Pennsylvania, USA: A preliminary assessment of the relative influences of climate, river discharge and suburban development. Water Resour., 37, 1737-1748, doi: 10.1016/S0043-13 54(02)00574-2. [Link]

Kundzewicz, Z. W. and V. Krysanova, 2010: Climate change and stream water quality in the multi-factor context. Clim. Change, 103, 353-362, doi: 10.1007/s1 0584-010-9822-9. [Link]

Loë, R. D., R. Kreutzwiser, and L. Moraru, 2001: Adaptation options for the near term: Climate change and the Ca- nadian water sector. Global Environ. Change, 11, 231245, doi: 10.1016/S0959-3780(00)00053-4. [Link]

Mantua, N., I. Tohver, and A. Hamlet, 2010: Climate change impacts on streamflow extremes and summertime stream temperature and their possible consequences for freshwater salmon habitat in Washington State. Clim. Change, 102, 187-223, doi: 10.1007/s10584-010 -9845-2. [Link]

Murdoch, P. S., J. S. Baron, and T. L. Miller, 2000: Potential effects of climate change on surface-water quality in North America. J. Am. Water Resour. Assoc., 36, 347366, doi: 10.1111/j.1752-1688.2000.tb04273.x. [Link]

Oehlert, G. W., 1992: A note on the Delta Method. Am. Stat., 46, 27-29.

Ogrosky, H. O. and V. Mockus, 1964: Hydrology agricultural lands. In: Chow, V. T. (Ed.), Handbook of Applied Hydrology, McGraw-Hill, New York.

Pickering, N. B., J. R. Stedinger, and D. A. Haith, 1988: Weather input for nonpoint-source pollution models. J. Irrig. Drain. Eng., 114, 674-690, doi: 10.1061/(AS CE)0733-9437(1988)114:4(674). [Link]

Ruosteenoja, K., H. Tuomenvirta, and K. Jylhä, 2007: GCM-based regional temperature and precipitation change estimates for Europe under four SRES scenarios applying a super-ensemble pattern-scaling method. Clim. Change, 81, 193-208, doi: 10.1007/s10584-0069222-3. [Link]

Rush, R., J. Ivey, R. de Loë, and R. Kreutzwiser, 2004: Adapting to climate change in the Oldman River Watershed, Alberta: A discussion paper for water stakeholders. Guelph Water Management Group.

Sadler, B., 1994: Environmental assessment and development policymaking. In: Goodland, R. and V. Edmundson (Eds.), Environmental Assessment and Development, World Bank, Washington, DC.

Schneiderman, E., M. Jarvinen, E. Jennings, L. May, K. Moore, P. S. Nadern, and D. Pierson, 2010: Modeling the effects of climate change on catchment hydrology with the GWLF model. In: George, G. (Ed.), The impact of climate change on European lakes, Aquatic Ecology Series, 4, 33-50.

Selker, J. S. and D. A. Haith, 1990: Development and testing of single-parameter precipitation distributions. $\mathrm{Wa}$ ter Resour. Res., 26, 2733-2740, doi: 10.1029/WR02 6i011p02733. [Link]

Tung, C. P. and D. A. Haith, 1995: Global-warming effects on New York streamflows. J. Water Resour. Plan. Manage., 121, 216-225, doi: 10.1061/(ASCE)0733-94 96(1995)121:2(216). [Link]

Wetterhall, F., A. Bárdossy, D. Chen, S. Halldin, and C. $\mathrm{Xu}, 2009$ : Statistical downscaling of daily precipitation over Sweden using GCM output. Theor. Appl. Climatol., 96, 95-103, doi: 10.1007/s00704-008-0038-0. [Link] 